\title{
Incorporação de Aspectos de Colaboração no Dicionário da Língua Brasileira de Sinais: uma Análise da Viabilidade
}

\author{
Lucas Eduardo Rosa de Freitas ${ }^{1}$, Carla Diacui Medeiros Berkenbrock ${ }^{1}$, \\ Fabıla Sucupira Ferreira Sell ${ }^{1}$
}

${ }^{1}$ Universidade do Estado de Santa Catarina (UDESC)

Joinville - SC - Brasil

lucas.freitas@edu.udesc.br, \{carla.berkenbrock, fabiola.sell\}@udesc.br

\begin{abstract}
This paper aims to perform a feasibility analysis to promote collaboration in the Brazilian Sign Language Dictionary (DLBS). The results will be used in the development of a prototype that will be tested by deaf and listeners interested in the learning of the Brazilian Sign Language (LIBRAS). Communication is a fundamental factor for the exchange of feelings and knowledge. The communication under study is sign language, which arises in the communities of deaf people and happens visually-spatially rather than through sounds. Several tools have been developed to facilitate the learning of this language, for instance DLBS. However, prior analysis to DLBS shows that the tool has no aspects of collaboration, which makes it static reducing its effectiveness.
\end{abstract}

Resumo. Este trabalho propõe a realização de uma análise de viabilidade para promover colaboração no Dicionário da Língua Brasileira de Sinais V3 - 2011 (DLBS). Os resultados obtidos serão utilizados no desenvolvimento de um protótipo testado por surdos e ouvintes interessados em aprender a Língua Brasileira de Sinais (LIBRAS). A comunicação é um fator fundamental para a troca de sentimentos e conhecimento. A comunicação em estudo é a língua de sinais, que surge nas comunidades de pessoas surdas e acontece de forma visual-espacial e não por meio da emissão de sons. Diversas ferramentas foram desenvolvidas com o objetivo de facilitar o aprendizado desta língua, como o DLBS. Contudo, em análise prévia ao DLBS percebe-se que a ferramenta não apresenta aspectos de colaboração, o que a torna estática reduzindo sua efetividade.

\section{Introdução}

A comunicação, seja por meio da voz, de sinais ou da escrita, é a maior fonte de transmissão de sentimentos e conhecimentos. A comunicação é realizada por meio da transferência de informação sob duas condições principais: (i) presença de um emissor e um receptor; (ii) transmissão de mensagens (CORRAZE, 1982). A comunicação pode ser realizada de forma verbal ou não-verbal. A comunicação não-verbal exerce fascínio sobre a humanidade desde seus primórdios, pois envolve manifestações de comportamento não expressas por palavras, como os gestos, expressões faciais, orientações do corpo e posturas (SILVA et al., 2000).

A comunicação verbal difere da não-verbal uma vez que a primeira apresenta signos linguísticos, que podem ser tanto palavras como sinais. Um sinal é um signo 
linguístico, composto por um significante e um significado, assim, a língua de sinais se enquadra na comunicação verbal. O principal meio de comunicação dos surdos é a língua de sinais, que se refere a estruturas linguísticas utilizadas pela comunidade surda na expressão e elaboração do pensamento e na comunicação. As línguas de Sinais são línguas naturais que se desenvolvem no meio onde vive a comunidade surda.

Segundo Padden e Humphries (1989) as linguagens de sinais são inteiramente formadas pela linguagem natural encadeada com os valores culturais e comportamento social das comunidades surdas e difere da maioria das linguagens faladas, pelas comunidades ouvintes. As línguas de sinais apresentam o mesmo tipo de princípios organizacionais e parâmetros que formam a gramática das línguas (QUADROS, 1997). De acordo com Costa et al. (2017) desenvolver condições de acessibilidade comunicacional bilíngue de pessoas surdas pode ser uma das estratégias para lhes garantir melhores condições de acesso às informações e à comunicação. Considerando a complexidade em aprender a língua de sinais, têm-se diversas ferramentas para o auxílio, suporte de ouvintes ou surdos.

O Dicionário da Língua Brasileira de Sinais V3 - 2011 é a ferramenta de estudo deste trabalho. Os usuários desta ferramenta, sendo eles surdos ou ouvintes, buscam aprimorar ou aprender termos na Língua Brasileira de Sinais (LIBRAS). Ao realizar a pesquisa do termo desejado, o sinal pode ser mostrado nos formatos de vídeo e foto, facilitando o entendimento do sinal. Além disso, é apresentado um exemplo com uma frase que utiliza o termo que foi pesquisado, apresentando também a frase escrita em Libras. Contudo, em uma análise prévia no dicionário de sinais foram encontradas limitações para o uso de forma mais eficaz, tais como a falta de colaboração entre os usuários, bem como a falta de regionalismo. Regionalismo se dá por características ou tradições de regiões, na qual cada estado tem suas peculiaridades, que as diversificam dos outros.

Sendo assim, o presente trabalho propõe a realização de uma análise da viabilidade da incorporação de aspectos de colaboração no Dicionário da Língua Brasileira de Sinais, visando possibilitar uma maior comunicação entre seus usuários.

\section{Trabalhos Relacionados}

A literatura apresenta poucas soluções para os problemas gerados pela falta de colaboração em softwares orientados à língua de sinais. Os problemas relacionados com a falta de comunicação com os surdos, bem como com seus intérpretes também é pouco relatada.

\section{Tabela 1. Artigos Relacionados}

\begin{tabular}{llll} 
Artigos & Problemática & Software & Colaboração \\
\hline \hline Pontes e Orth (1999) & $\begin{array}{l}\text { Introdução da língua de sinais } \\
\text { em interface de um software }\end{array}$ & Sim & Não \\
\hline Ferreira-Brito (1986) & Integração social do surdo & Não & Não \\
\hline Faulstich (2006) & $\begin{array}{l}\text { Dicionário enciclopédico ilus- } \\
\text { trado de Libras }\end{array}$ & Não & Não \\
\hline Lacerda e Poletti (2004) & Inclusão de alunos surdos & Não & Não \\
\hline \hline
\end{tabular}

A Tabela 1 apresenta uma síntese de trabalhos relacionados com a língua de si- 
nais. É possível observar que se trata de trabalhos que apenas apresentam o problema na comunicação, mostrando a dificuldade para realizar uma boa comunicação entre os surdos e os ouvintes.

\section{Problema e Proposta}

O Dicionário da Língua Brasileira de Sinais dispõe de uma única tela, na qual são apresentadas as informações aos usuários, como mostra a Figura 1. O dicionário permite realizar a pesquisa por palavra, assunto, acepção ou por algum exemplo. A acepção equivale ao sentido que cada frase ou palavra apresenta de acordo com o seu contexto, como por exemplo, a palavra estrela pode estar sendo referenciada como um astro do rock ou um corpo celeste. Após ser feita a pesquisa do termo desejado são apresentados os resultados.

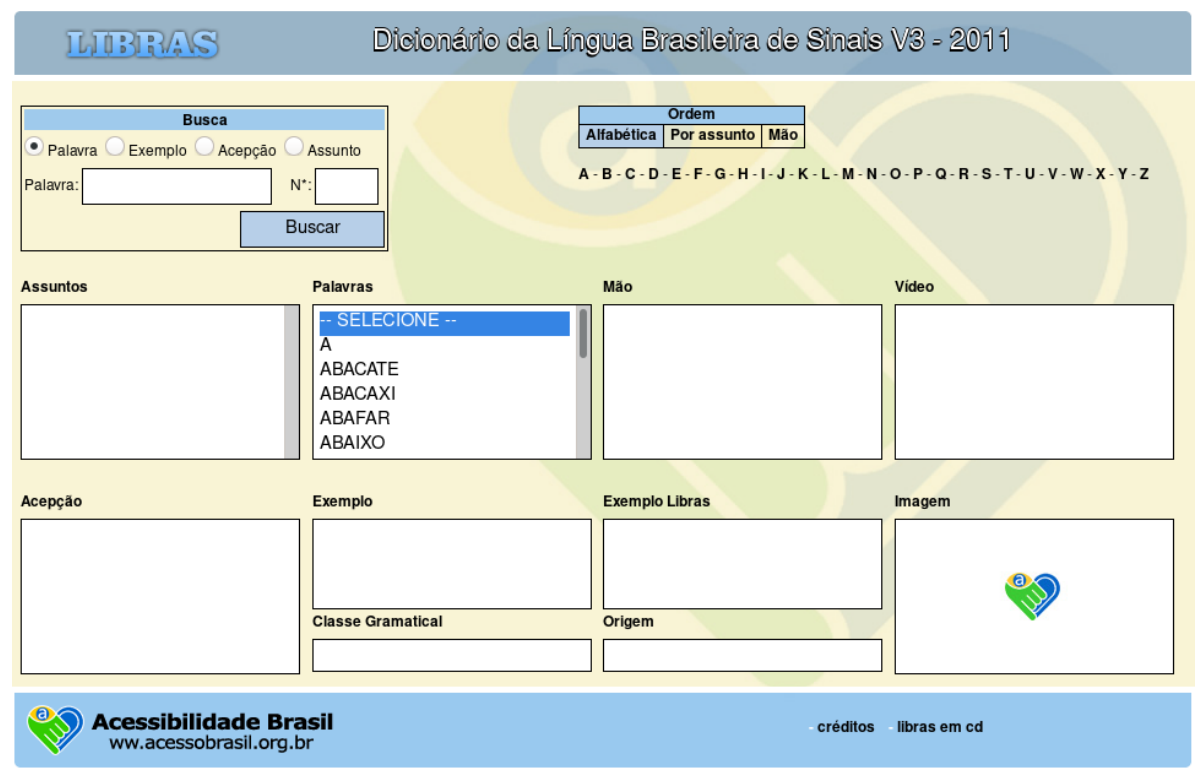

Figura 1. Tela dicionário Libras

Em sinais, o resultado é mostrado no formato da configuração de mão e em video, detalhando como o sinal é feito. Além destes resultados é apresentado um exemplo com uma frase em português e uma frase pronta para ser sinalizada em Libras. A Figura 2 apresenta uma pesquisa com a palavra Aeromoça.

Em uma análise realizada no dicionário foram encontradas limitações para o seu uso, onde a principal é a falta de colaboração. Com isso a ferramenta se torna estática, impossibilitando que usuários possam adicionar novos termos e sinais. A falta de colaboração também gera outros problemas, como a falta do regionalismo, característica própria das línguas naturais, como é o caso das Línguas de Sinais. Assim como na comunicação falada, a língua de sinais possui alterações de acordo com o estado onde cada surdo se encontra. A Figura 3 mostra a variação do sinal da cor verde, nos estados de São Paulo, Rio de Janeiro e Curitiba. Assim, em muitas situações tem-se sinais completamente diferentes para o mesmo significado.

O presente trabalho propõe a análise da viabilidade da incorporação de aspectos de colaboração no Dicionário da Língua Brasileira de Sinais. Entre eles, está a incorporação do regionalismo, apresentando os sinais de acordo com a região pesquisada. A análise 


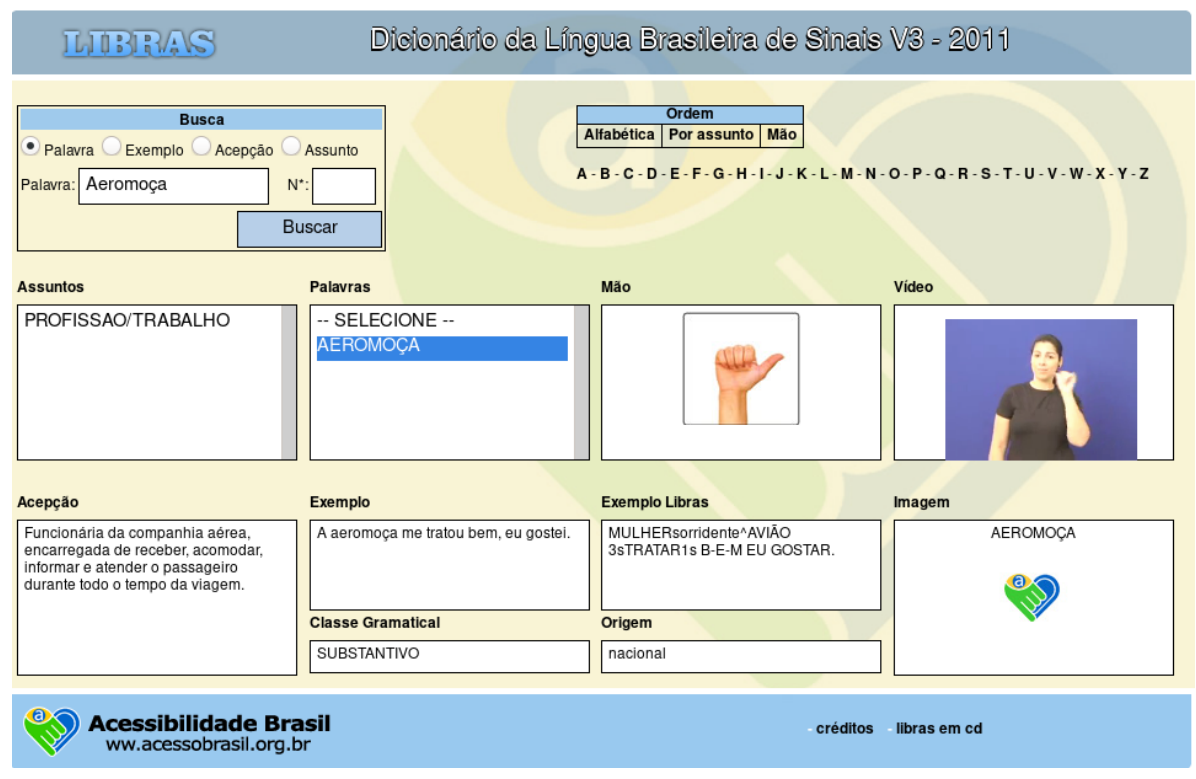

Figura 2. Busca pela palavra Aeromoça

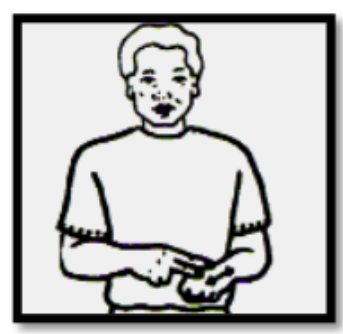

Rio de Janeiro

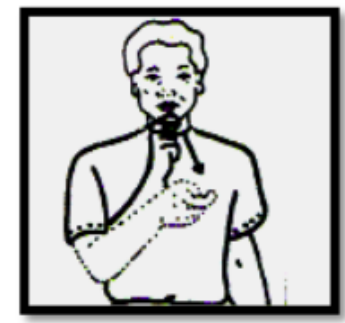

São Paulo

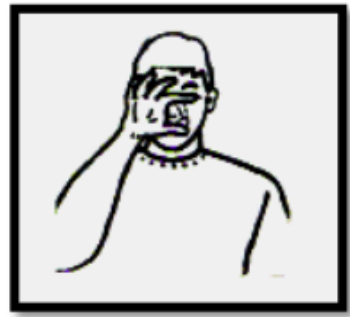

Curitiba

Figura 3. Variação regional do sinal da cor verde

busca identificar problemas na ferramenta que possam ser explorados. Para isso, serão utilizadas as técnicas de design participativo e design centrado no usuário. O design participativo será empregado para a construção da interface do protótipo da ferramenta. Essa prototipação se dá a partir da coleta de informações com o usuário para compreender as suas reais necessidades. Será utilizado protótipo de baixa fidelidade para apresentar o leiaute da tela. $\mathrm{O}$ design centrado no usuário, concentra as necessidades e requisitos nos usuários, com o objetivo de produzir ferramentas altamente utilizáveis e acessíveis.

Considerando que em uma ferramenta de interação a interface é parte fundamental, pois é a partir dela que o usuário interage com a aplicação (ANTUNES et al., 2008), (SANTOS; FERREIRA; PRATES, 2012), a interface será avaliada por meio do design baseado em cenários e do design de interação. Assim, espera-se verificar se a ferramenta contempla os aspectos de colaboração esperados pelos usuários, que são pessoas surdas ou interessadas em aprender Libras. Para Nielsen (1994) o usuário é fundamental na avaliação das funcionalidades da ferramenta, pois ele está diretamente em contato com a aplicação. 


\section{Considerações}

O sujeito surdo tem a língua portuguesa (principalmente a modalidade escrita), como segunda língua, cujo aprendizado se dá de forma não-natural. Sendo a Língua Brasileira de Sinais a língua natural das pessoas surdas, faz-se necessário possibilitar às pessoas surdas e ouvintes seu aprendizado e uso corrente, principalmente nas relações escolares, familiares e profissionais. Contudo, as ferramentas para o auxílio dos surdos e ouvintes ainda não estão preparadas para a colaboração. Assim, tais ferramentas, como é o caso do Dicionário da Língua Brasileira de Sinais, ainda apresentam conteúdo estático e limitado. Essas ferramentas podem ser úteis para aqueles que buscam aprender a se comunicar em Libras de forma eficaz. Também é importante que os surdos possam ter uma experiencia agradável, motivando o uso de tais ferramentas no ensino ou na comunicação básica.

\section{Referências}

ANTUNES, P. et al. Structuring dimensions for collaborative systems evaluation. ACM Comput. Surv., ACM, New York, NY, USA, v. 44, n. 2, p. 8:1-8:28, mar. 2008. ISSN 0360-0300. Disponível em: 〈http://doi.acm.org/10.1145/2089125.2089128〉.

CORRAZE, J. As comunicações não verbais. Rio de Janeiro: Zahar, 1982.

COSTA, S. E. da et al. Ilibras como facilitador na comunicação efetiva do surdo: Uma ferramenta colaborativa móvel. XIV Simpósio Brasileiro de Sistemas Colaborativos SBSC, São Paulo, Brasil, p. 1269-1283, 2017.

FAULSTICH, E. Dicionário enciclopédico ilustrado trilingüe da língua de sinais brasileira. Perspectiva, v. 24, n. 3, p. 197-201, 2006.

FERREIRA-BRITO, L. Integração social do surdo. Trabalhos em Linguística Aplicada, v. 7, 1986.

LACERDA, C. d.; POLETTI, J. E. A escola inclusiva para surdos: a situação singular do intérprete de língua de sinais. $27^{a}$ Reunião Anual da Associação Nacional de Pesquisa em Educação, 2004.

NIELSEN, J. Usability engineering. San Diego, Calif: Elsevier, 1994.

PADDEN, C.; HUMPHRIES, T. Deaf in america: Voices from a culture. Ear and Hearing, v. 10, n. 2, p. 139, 1989.

PONTES, A. M.; ORTH, A. I. Uma proposta de interface de software orientada à linguagem de sinais. In: Anais. II Workshop sobre Fatores Humanos em Sistemas Computacionais. Campinas: Unicamp. São Paulo: Atas, 1999. p. 1-6.

QUADROS, R. M. Educação de surdos-aquisição da linguagem. 1ª . Edição. Porto Alegre, 1997.

SANTOS, N. S.; FERREIRA, L. S.; PRATES, R. O. An overview of evaluation methods for collaborative systems. In: IEEE. 2012 Brazilian Symposium on Collaborative Systems. São Paulo, 2012. p. 127-135.

SILVA, L. M. G. d. et al. Comunicação não-verbal: reflexões acerca da linguagem corporal. Revista latino-americana de enfermagem, SciELO Brasil, 2000. 